\title{
ADAPTIVE COMFORT PADA GRAND STUDIO PROGRAM STUDI ARSITEKTUR FAKULTAS TEKNIK UNIVERSITAS MALIKUSSALEH
}

\author{
Atthaillah $^{1 *}$, Eri Saputra², Muhammad Iqbal ${ }^{3}$ \\ Universitas Malikussaleh \\ e-mail: *1atthaillah@unimal.ac.id,2erisaputra@unimal.ac.id,iqbal_arch@yahoo.co.id
}

\begin{abstract}
Abstrak_ Ruang Grand Studio Program Studi Arsitektur Fakultas Teknik Universitas Malikussaleh (GS-PAFT) merupakan satu ruang studio baru yang menggunakan penghawaan alami pada prodi Arsitektur universitas tersebut. GS-PAFT merupakan ruang studio yang paling luas yang dapat menampung 60 orang mahasiswa dengan luas 168.48 m2dan baru digunakan satu semester. Dalam penggunaannya, dirasakan kondisi termal yang tidak nyaman baik bagi mahasiswa maupun tenaga pengajar. Studi ini melakukan investigasi untuk membuktikan sensasi ketidaknyamanan subjektif tersebut dengan data sehingga bisa dipertanggung jawabkan secara objektif dengan pengukuran adaptive comfort. Tujuannya adalah untuk memberikan data sensasi termal sehingga pihak prodi arsitektur dapat mengambil langkah yang benar untuk penyelesaian masalah tersebut. Metode yang dipakai adalah metode simulasi komputer dengan teknik parametrik menggunakan Rhinoceros, Grasshopper dan Ladybug \& Honeybee. Ruang GS-PAFT dibagi menjadi sembilan zona berdasarkan orientasi dan modul bangunan untuk memudahkan analisis. Simulasi dilakukan dari pukul 08.00 sampai 17.00 yang merupakan waktu pemakaian ruang pada hari kerja. Hasil menunjukkan kurang dari $40 \%$ waktu sepanjang tahun dirasakan nyaman. Zona yang paling nyaman dan paling tidak nyaman secara berurutan adalah zona 8 (Timur, tidak terpapar matahari) dan zona 20 (Barat Daya, terekspos matahari) dengan persentase waktu nyaman tahunan 39.23\% dan 33.53\%.
\end{abstract}

Kata kunci : Adaptive Comfort; Sensasi Termal; Simulasi Kenyamanan Termal; Metode Parametrik; Ruang Studio.

\begin{abstract}
Grand Studio Program Studi Arsitektur Fakultas Teknik Universitas Malikussaleh (GS-PAFT) was a latest naturally ventilated studio space within the department of Architecture of Universitas Malikussaleh. GS-PAFT was the largest studio which accommodated 60 students with the area of $168.48 \mathrm{~m} 2$ and it had been utilized only for one semester. The thermal sensation of the space was uncomfortable both for students and lecturers who had used the studio. This study invenstigated the subjective thermal sensation with an objective measurement of adaptive comfort. The paper was aimed at providing data of thermal sensation, thus, it could guide the department of architecture to solve the thermal comfort problem. This study used computer simulation method with parametric technic using Rhinoceros, Grasshopper, Ladybug \& Honeybee. The GS-PAFT was divided into nine zones based on its orientation and the building modular for easier analysis. Simulation was conducted from 08:00 A.M. to 05:00 P.M. which was the time of the space was utilized within the working days. The result showed less than $40 \%$ of the time from the whole year was thermally comfortable. The most comfortable and discomfortable zones consecutively were zone 8 (East, no sun exposure) and zone 20 (South West, sun exposed) which revelead $39.23 \%$ and 33.53\% of thermally comfortable time during the whole year.
\end{abstract}

Keywords : Adaptive Comfort; Thermal Sensation; Thermal Comfort Simulation; Parametric Method, Architecture Studio.

\footnotetext{
${ }^{1}$ Jurusan Arsitektur Universitas Malikussaleh

${ }^{2}$ Jurusan Arsitektur Universitas Malikussaleh

${ }^{3}$ Jurusan Arsitektur Universitas Malikussaleh
} 


\section{ADAPTIVE COMFORT PADA GRAND STUDIO PROGRAM STUDI ARSITEKTUR FAKULTAS TEKNIK UNIVERSITAS MALIKUSSALEH

\section{PENDAHULUAN}

Gedung Program Studi Arsitektur Fakultas Teknis (PAFT) Universitas Malikussaleh berlokasi di Jalan Sultan Nahrasiyah Kota Lhokseumawe, Aceh, Indonesia. Baru-baru ini pada gedung PAFT dikonstruksikan Grand Studio yang merupakan sebuah ruang belajar baru untuk mata kuliah studio pada program studi tersebut dengan luas $168.48 \mathrm{~m}^{2}$. Selanjutnya, Grand Studio ini disebut dengan GS-PAFT. Ruangan tersebut terletak di lantai 3 (tiga) gedung PAFT. Penggunaan GS-PAFT baru pertama kali digunakan pada semester genap 2016/2017. Ruang studio tersebut dapat menampung 60 (enam puluh) orang mahasiswa. Selanjutnya ruang studio tersebut tidak menggunakan penghawaan buatan. Hal lainnya adalah semua jendela bisa dibuka tutup sebesar $30 \%$ dari ukuran jendela dan terletak pada sisi Utara dan Selatan ruang.

Selain untuk perkuliahan mata kuliah studio, ruangan tersebut juga didesain untuk dapat menampung kegiatan-kegiatan seperti kuliah umum, seminar dan kegiatan akademik lainnya seperti diskusi informal. Dari pengalaman penulis menggunakan ruangan tersebut beberapa waktu mengalami masalah ketidaknyaman termal dan merasakan suhu dalam ruangan telalu panas. Kondisi ketidaknyaman ini juga dialami oleh tanaga pengajar dan mahasiswa lainnya. Walaupun ruangan memiliki sistem ventilasi silang, namun pada jam-jam tertentu, terutama pada siang hari ruangan menjadi sangat panas. Hal ini dapat terjadi jika terdapat salah satu bidang dinding yang terekpos dengan radiasi matahari. Hal ini menunjukkan bahwa Mean Radian Temperature (MRT) berkontribusi sangat penting dalam menentukan kenyamanan termal (Kamaruzzaman \& Tanzilan 2012, 87). Tentunya, kondisi ini tidak dapat menciptakan ruang studio multiguna yang dapat memberikan kenyamanan termal untuk kegiatan-kegiatan akademik lainnya.

Kondisi ketidaknyaman termal yang dialami tentunya berpengaruh pada produktifitas tenaga pengajar maupun mahasiswa yang menggunakan ruangan tersebut. Hal ini didukung oleh para peneliti seperti Hoof, Mazej dan Heusen (2010), Li dan Yao (2012), Zailani, Hamidon, Hussin, Hamzas dan Hadi (2012), Hussein dan Rahman (2009) serta Teli, Jeutsch dan James lewat penelitian mereka tentang ruang kelas dengan penghawaan alami pada tahun 2012 yang lalu (Alozie, Ifebi dan Eze 2015, 105). Indikasi produktifitas buruk menyebabkan tidak terciptanya pengajaran yang berkualitas. Alozie, Ifebi dan Eze (2015a, 207) mendukung hal ini dengan mengatakan bahwa mahasiswa arsitektur membutuhkan kenyamanan secara termal untuk dapat menunjukan performa yang optimal. Kondisi ini tidak dapat dibiarkan lebih lama dan membutuhkan kajian yang lebih akurat untuk dapat memberikan solusi terhadap permasalahan termal seperti telah disebutkan sebelumnya. Hal ini penting agar tidak salah mengambil langkah perbaikan kondisi termal dengan tetap mempertimbangkan efisiensi pemakaian energi. Sehingga permasalahan produktifitas kegiatan belajar mengajar tetap dapat dipenuhi tanpa berkontribusi terlalu banyak pada penggunaan energi listrik yang signifikan.

Studi ini mencoba mengkaji sensasi termal yang dirasakan secara subjektif seperti telah dijelaskan sebelumnya oleh pungguna ruangan tersebut dalam bentuk data dan kajian yang dapat secara objektif dipertanggung jawabkan. Untuk itu, penelitian ini melakukan mengukur kenyamanan termal pada GS-PAFT dengan menggunakan perhitungan adaptive comfort menggunakan simulasi komputer.

\section{ADAPTIVE COMFORT}

Perkembangan pengukuran kenyamanan termal berkembang dalam waktu yang sangat lama sejak pertama sekali teori Predicted Mean Vote (PMV) dikenalkan oleh Fanger pada 1972 (Santamouris 2006, 1). Pada awal abad ke dua puluh satu baru teori kenyamanan termal baru 


\section{ADAPTIVE COMFORT PADA GRAND STUDIO PROGRAM STUDI ARSITEKTUR FAKULTAS TEKNIK UNIVERSITAS MALIKUSSALEH \\ Eri Saputra, Muhammad Iqbal}

Atthaillah,

yang dikenal dengan adaptive comfort diintegrasikan dalam ASHRAE standar 55 pada tahun 2004 (Santamouris 2006, 3). Diantara para peneliti yang mendukung teori adaptive comfort adalah Humpreys dan Nicol (2000) dan Nicol (2002) yang kemudian usulan persamaan mereka diintegrasikan kedalam ASHRAE Standar 55 (Santamouris 2006, 3). Pada standar tersebut kenyamanan termal didefnisikan sebagai kondisi pikiran yang menyatakan tingkat kepuasan sesuai dengan kondisi lingkungan termal ( ASHRAE Standard 55 2010).

Perbedaan utama antara teori PMV dan Adaptive Comfort terletak pada kondisi mempertimbangkan kondisi bangunan yang memakai atau tidak menggunakan sistem penghawaan buatan. PMV bekerja akurat untuk bangunan yang menggunakan sistem penghawaan mekanik. Sementara, Adaptive Comfort diperuntukkan pengukuran kenyamanan termal pada bangunan-bangunan dan ruang-ruang yang mengintegrasikan sistem penghawaan alami ( ASHRAE Standard 55 2010). Kondisi penghawaan alami adalah kondisi pada ruang GS-PAFT. Ketidaktepatan pengukuran kenyamanan termal menggunakan PMV untuk ruang yang memiliki penghawaan alami. Hal ini sebagaimana ditunjukkan pada penelitian oleh Baruah, Singh, \& Mahapatra $(2014,6)$ yang mendapatkan deviasi yang besar dari hasil pengukuran aktual.

Dalam Adaptive Comfort pengguna bangunan diasumsikan dapat melakukan adaptasi kondisi psikologis dalam sebuah ruangan (de Dear \& Brager 2002). Misalnya, dengan membuka jendela jika kondisi menjadi panas atau menggunakan pakaian yang sesuai dengan kondisi termal pada ruangan (van Treeck, Frisch, Egger, \& Rank 2009, 1374). Jadi, tingkah laku pengguna bangunan menjadi pertimbangan untuk pengukuran kenyamanan termal. Hal ini sangat berbeda dengan PMV yang menganggap pengguna bertindak statis dan tidak melakukan upaya apapun untuk memperbaiki kondisi lingkungan jika keadaan menjadi tidak nyaman. Pengukuran PMV untuk kondisi ruangan untuk kondisi iklim dalam ruangan yang statis juga didukung oleh van Treeck, Frisch, Egger, \& Rank $(2009,1374)$. Oleh sebab itu, penelitian ini menggunakan metode simulasi dengan pengukuran adaptive comfort.

\section{METODE}

Penelitian ini dilakukan dengan metode simulasi komputer dengan menggunakan piranti Ladybug versi 0.0.64 dan Honeybee 0.0.61. Metode simulasi dipilh karena kemudahan, ketepatan dan kecepatan yang dimilki untuk analisis dan evaluasi. Simulasi merupakan pengejawantahan kondisi kelakuan maupun karakteristik dari sebuah sistem dengan menggunakan sistem tertentu yang dapat mewakili seperti dengan menggunakan software komputer (Groat \& Wang 2013, 350). Ladybug dan Honeybee merupakan dua plug-ins yang berjalan pada interface Grasshopper dan Rhinoceros yang dapat membantu melakukan analisis lingkungan. Ladybug dapat bekerja dengan data cuaca untuk Energy Plus (.EPW). Data meteorologi untuk Lhokseumawe dalam format .EPW digunakan pada studi ini. Data cuaca dari badan meteorologi tersebut dapat divisualkan dalam bentuk grafik dua dan tiga dimensi sehingga dapat membantu proses evaluasi pada analisis lingkungan. Sementara, Honeybee dapat menghubungkan Grasshopper dengan empat engine simulasi yang sudah tervalidasi seperti Energy Plus, Radiance, Daysim dan Open Studio yang dapat digunakan untuk mengevaluasi konsumsi energi bangunan, kenyamanan termal dan pencahayaan alami (Roudsari dan Pak 2013). Studi ini menggunakan Ladybug dan Honeybee dan Energy Plus 8.6.0 untuk simulasi kenyamanan termal dengan adaptive comfort metric pada GS-PAFT.

Selanjutnya, pengukuran data langsung seperti dimensi dan material yang digunakan pada ruang GS-PAFT. Setelah itu melakukan pengukuran dan analisa bangunan perimeter yang memberikan dampak pembayangan terhadap ruang yang menjadi kajian. Untuk bangunan perimeter, tidak ada yang melebihi elevasi dari ruang GS-PAFT. Ini artinya ruang GS-PAFT terekspos langsung dengan matahari tanpa bangunan penghalang. Data hasil pengukuran dan pengamatan ini dijadikan acuan untuk permodelan digital dengan menggunakan Grasshopper. 


\section{ADAPTIVE COMFORT PADA GRAND STUDIO PROGRAM STUDI ARSITEKTUR FAKULTAS TEKNIK UNIVERSITAS MALIKUSSALEH \\ Eri Saputra, Muhammad Iqbal}

Atthaillah,

Ruangan GS-PAFT dimodelkan parsial sebagai bagian dari bangunan utama. Untuk itu, sisi-sisi interior yang berbatasan dengan zona lainnya dan lantai ruangan dimodelkan sebagai adiabatic. Hal ini disebabkan dinding dan lantai tersebut tidak terekspos dengan kondisi eksterior dan diasumsikan tidak ada transfer energi dari dinding dan lantai tersebut. Sementara atap, bukaan dan dinding-dinding eksterior dimodelkan sesuai dengan kondisi eksisting baik dimensi, material dan konstruksinya.

Data permodelan yang berbentuk Boundary Representative (Brep) kemudian dikonversikan menjadi zone dengan komponen Honeybee. Hal ini dilakukan karena engine simulasi Energy Plus hanya mengenal zone sehingga proses simulasi dapat dieksekusi. Zones yang dimaksud dibagi berdasarkan pertimbangan orientasi dan letaknya dalam ruangan GS-PAFT. Untuk memudahkan identifikasi dari setiap zone maka ukuran zones disesuaikan dengan ukuran modul bangunan. Pada ruang GS-PAFT dibagi menjadi 9 (sembilan) zones. Sementara properti termal material-material didefinisikan dengan komponen Honeybee sesuai dengan data eksisting. Selanjutnya, melakukan setting untuk parameter simulasi terkait kenyamanan termal. Setelah model dan setting selesai, maka, proses simulasi dilakukan dengan komponen simulasi Energy Plus yang sudah diintegrasikan kedalam Honeybee. Setelah mendapatkan hasil simulasi maka dengan menggunakan komponen Adaptive Comfort tool dari Ladybug tingkat kenyamanan dapat diketahui.

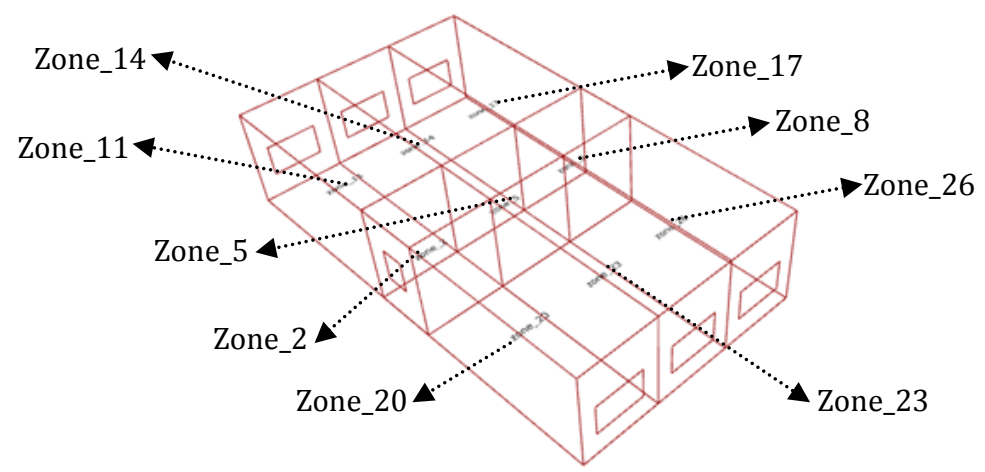

Gambar 1 : Ruang GS-PAFT dibagi menjadi 9 (sembilan) zones berdasarkan orientasi dan modul bangunan. Sumber: Penulis, 2017

Selain itu, hal yang menjadi pertimbangan adalah zone loads. Pada studi ini zone loads yang dimodifikasi sesuai dengan kondisi GS-PAFT adalah, Equipment Loads, Infiltration Loads dan Jumlah orang permeter luas ruangan. Zone loads lainnya seperti lighting density, ventilation per area, ventilation per person dan recirculated air per area dibiarkan default karena dinilai sudah sesuai dengan kondisi GS-PAFT. Untuk equipment load diasumsikan $5 \mathrm{~W} / \mathrm{m} 2$, hal ini disebabkan penggunaan area kerja melibatkan beberapa laptop dan perkakas untuk membuat gambar dan maket dari pengguna ruangan. Untuk beban infiltrasi diasumsikan sesuai dengan keadaan infiltrasi untuk rata-rata bangunan yaitu $0,0003 \mathrm{~m} 3 / \mathrm{s}$ per $\mathrm{m} 2$ fasade. Sementara untuk beban pengguna diasumsikan 60 orang dibagi dengan luas ruangan. Dalam hal ini didapatkan 0.3561 orang/m2.

Tabel 1. Energy Plus Zone Load yang digunakan pada studi ini.

\begin{tabular}{lc}
\hline \multicolumn{1}{c}{ Beban/Loads } & Angka Satuan \\
\hline Equipment load per area $(\mathrm{W} / \mathrm{m} 2)$ & 5 \\
\hline Infiltration rate per area $(\mathrm{m} 3 / \mathrm{s} \mathrm{per} \mathrm{m} 2$ facade) & 0.0003 \\
\hline Jumlah orang per meter luas (orang/m2) & 0.3561 \\
\hline (Sumber: Penulis, 2017) &
\end{tabular}

Selanjutnya, zone schedule, diasumsikan pola aktivitas dan penggunaan ruang sesuai dengan

kondisi di kantor kecil (small office). Small office occupancy dan activity digunakan dalam 


\section{ADAPTIVE COMFORT PADA GRAND STUDIO PROGRAM STUDI ARSITEKTUR FAKULTAS TEKNIK UNIVERSITAS MALIKUSSALEH \\ Eri Saputra, Muhammad Iqbal}

Atthaillah,

permodelan pada tulisan ini. Untuk hal ini diperoleh dari Honeybee_Call from EP Schedule Library. Simulasi kenyamanan termal dilakukan satu tahun untuk periode waktu dari pukul 08.00 sampai 17.00. Untuk dapat mengukur kenyamanan termal dengan adaptive comfort tool dari ladybug maka perlu mengaktifkan Energy Plus simulation output yang terkait dengan kenyamanan termal yaitu zone comfort metric. Setelah simulasi Energy Plus selesai maka komponen Honeybee_Read EP Result digunakan untuk dapat memperoleh data input perhitungan dengan Ladybug_Adaptive Comfort Calculator.

Lebih lanjut, komponen Ladybug_Adaptive Comfort Calculator merujuk pada ASHRAE Standard 55 revisi 2013. Pada studi ini, kondisi dianggap nyaman jika 90\% pengguna ruang merasakan kondisi memuaskan secara termal. Terakhir adalah memvisualkan data hasil perhitungan dengan Ladybug-3D Chart.

Konteks dimodelkan sesuai dengan kondisi eksisting yang ada. Bangunan sekeliling tidak ada yang menyamai elevasi ruang GS-PAFT. Artinya, ruang GS-PAFT tidak terhalang oleh bangunan sekeliling. Orientasi bangunan sesuai dengan kondisi lokasi gedung PAFT Universitas Malikussaleh. Sebagai catatan atap bangunan dimodelkan sebagai konteks karena merupakan zona yang diasumsikan tidak berkontribusi terhadap penyaluran panas kedalam ruang GS-PAFT.

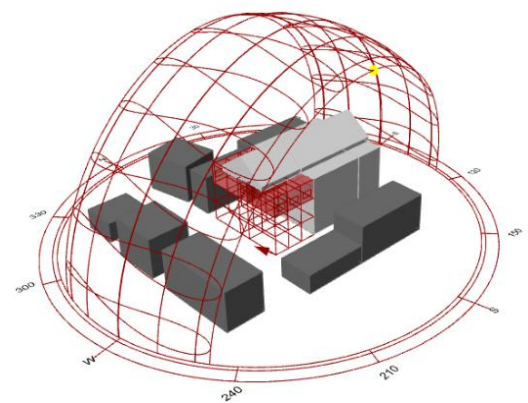

Gambar 2 : Model Ruang GS-PAFT (Warna Merah) untuk Simulasi Beserta Konteks. Panah Menunjukkan Arah Utara. Sumber: Penulis, 2017

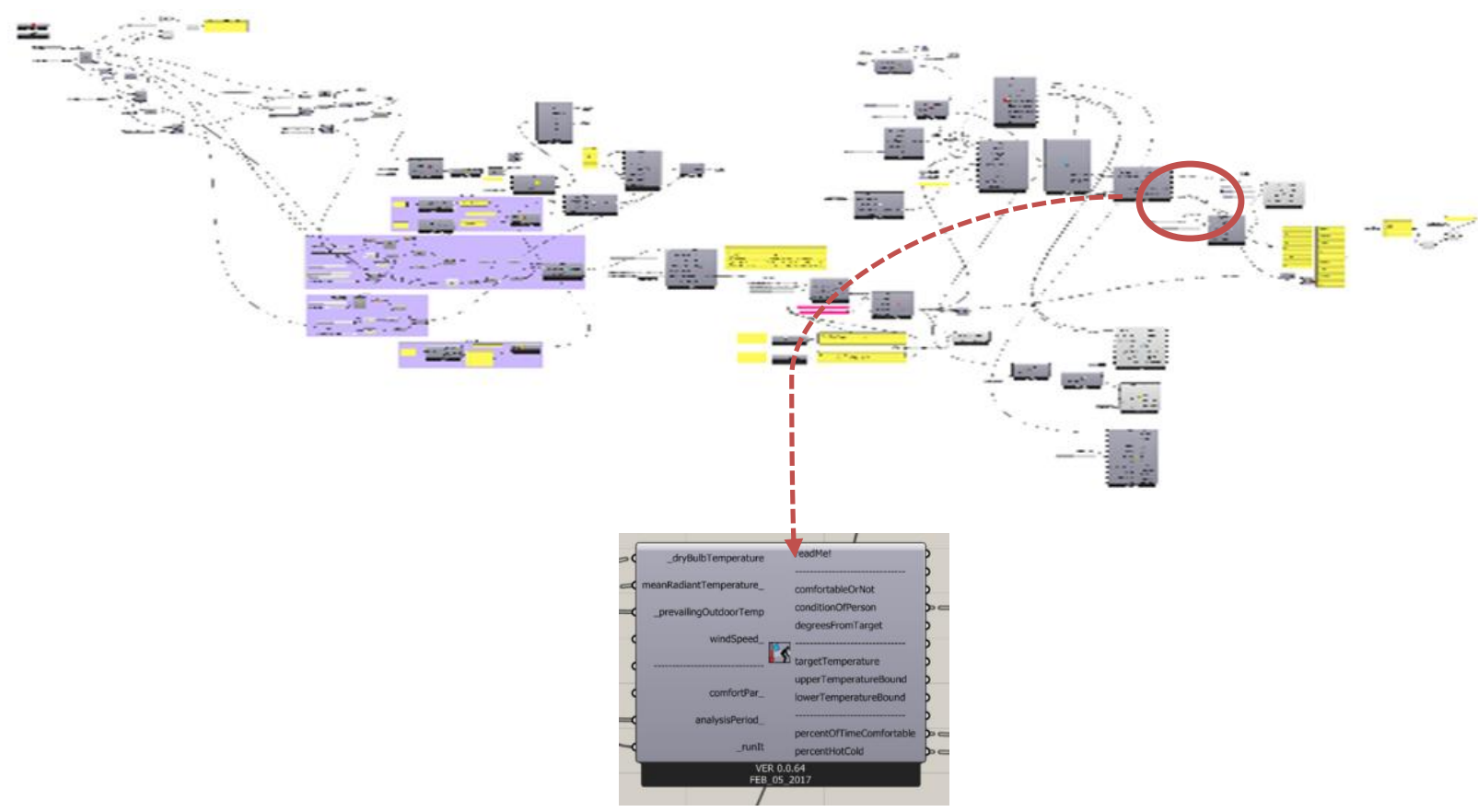

Gambar 3. Diagram Permodelan Parametrik dengan Grasshopper dan Komponen Ladybug_Adaptive Comfort Calculator, Menunjukkan Input dan Output yang Diperlukan untuk Bisa Mendapatkan Hasil Simulasi.

Sumber: Penulis, 2017 


\section{HASIL DAN PEMBAHASAN}

Hasil simulasi menunjukkan bahwa rata-rata kondisi nyaman dirasakan pada pagi hari. Menjelang siang kondisi panas mulai dirasakan sampai dengan sore hari. Hanya sebagian kecil porsi waktu yang dirasakan nyaman pada periode menjelang siang sampai sore hari. Tiga zona paling nyaman terletak pada bagian tengah ruangan yaitu zone_2, zone_5 dan zone_8. Zone_2 Hasil simulasi dapat dilihat pada grafik berikut:
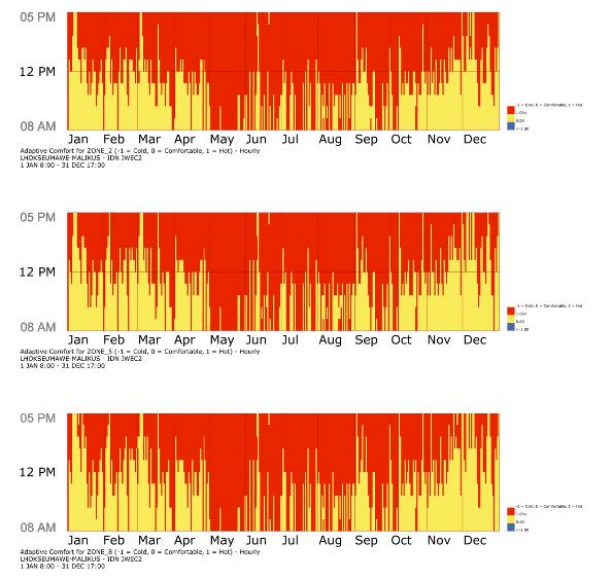

Gambar 4. Hasil Simulasi Zone_2, Zone_5 Dan Zone_8. Sumber: Penulis, 2017

Warna merah pada gambar tersebut menunjukkan kondisi tidak nyaman karena panas sedangkan warna kuning menunjukkan kondisi nyaman dari pengguna. Warna biru menunjukkan kondisi tidak nyaman karena dingin. Pada GS-PAFT hanya kondisi panas saja yang menyebabkan ketidaknyaman termal. Selanjutnya, persentase sensasi waktu nyaman sepanjang tahun didapatkan zone_2 sebesar 36.03\%, zone_5 sebesar $38.27 \%$ serta zone_8 sebesar 39.23\%. Sementara tiga zona nyaman berikutnya adalah zone_11, zone_14 dan zone_17 dengan persentase kenyamanan tahunan secara berurutan $34.08 \%$, 34.82\% dan 35.53\%.

Kondisi yang menyebabkan zona tersebut merupakan zona paling nyaman disebabkan tidak banyak area dinding yang terekspos dengan radiasi matahari. Hanya satu bagian dinding zone_2 saja yang terekspos sehingga membuat zona ini merupakan zona yang tidak nyaman diantara zona paling nyaman pada GS-PAFT.
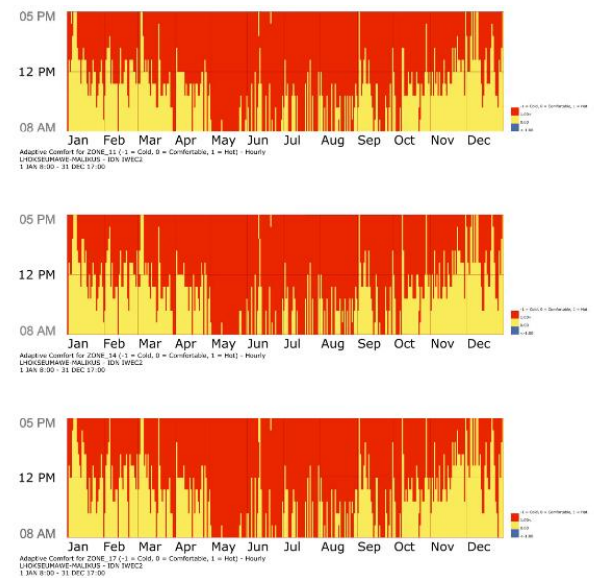

Gambar 5. Hasil Simulasi Zone_11, Zone_14 Dan Zone_17. Sumber: Penulis, 2017 


\section{ADAPTIVE COMFORT PADA GRAND STUDIO PROGRAM STUDI ARSITEKTUR FAKULTAS TEKNIK UNIVERSITAS MALIKUSSALEH \\ Eri Saputra, Muhammad Iqbal}

Atthaillah,

Terakhir adalah tiga zona paling tidak nyaman adalah zone_20, zone_23 dan zone_26. Secara berurutan persentase waktu nyaman sepanjang tahun yang dirasakan pada zona tersebut adalah $33.53 \%$, 34.25\% dan 34.11\%.
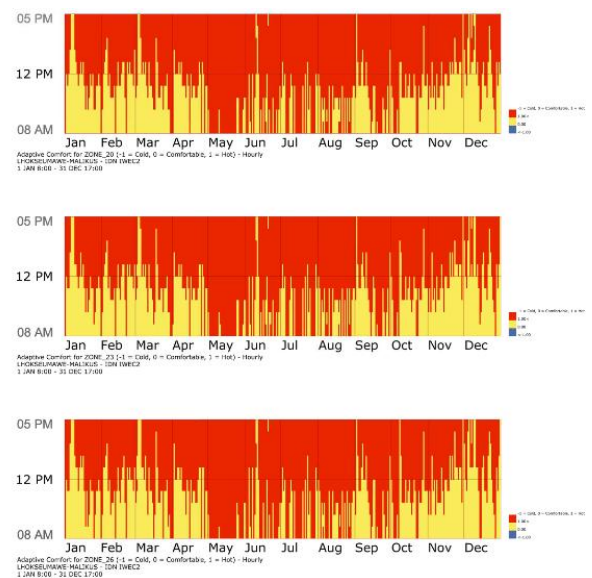

Gambar 6. Hasil Simulasi Zone_20, Zone_23 dan Zone_26. Sumber: Penulis, 2017

Dari data tersebut dapat dijelaskan bahwa dua zona yang paling tidak nyaman, zone_11 dan zone_20 murupakan dua zona yang dua bagian dindingnya terekspos langsung dengan matahari. Tentunya, hal ini berkonstribusi untuk menaikkan nilai mean radiant temperature (MRT) pada zona tersebut. Namun, hal yang membuat zone_20 menjadi zona paling tidak nyaman adalah dari seluruh zona yang ada adalah zona tersebut terletak di Barat Daya yang salah satu bidang dindingnya berada disisi Selatan. Letak tersebut membuat zone_20 menjadi zona yang terpapar matahari lebih lama dbandingkan dengan zone_11 yang terletak di Barat Laut. Hal tersebut diakibatkan oleh letak kota Lhokseumawe yang berada di Utara garis khatulistiwa. Letak geografis ini berpengaruh pada durasi peredaran matahari disebelah Selatan lebih lama dibandingkan dengan sisi Utara.

Berikutnya, dari sembilan zona yang disimulasikan terlihat bahwa sensasi paling tidak nyaman dirasakan pada bulan Mei. Pada bulan tersebut sensasi panas dirasakan mulai pagi sampai sore hari. Sensasi panas tersebut dirasakan disebagian besar waktu dibulan Mei. Periode bulan Mei sampai September merupakan periode tidak nyaman dirasakan pada ruang GS-PAFT. Berikut merupakan gambar grafik kenyamanan seluruh zona pertahun.

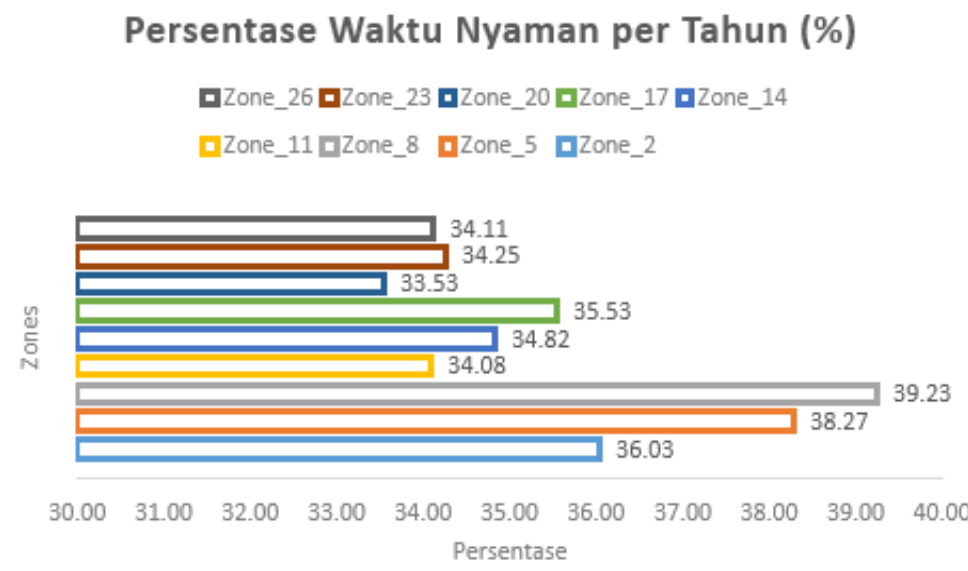

Gambar 7. Grafik persentase waktu nyaman pertahun seluruh zona. Sumber: Penulis, 2017 


\section{ADAPTIVE COMFORT PADA GRAND STUDIO PROGRAM STUDI ARSITEKTUR FAKULTAS TEKNIK UNIVERSITAS MALIKUSSALEH \\ Atthaillah, \\ Eri Saputra, Muhammad Iqbal}

Dari Gambar 7 diatas kelompok zona Tengah dan Utara menunjukkan tren semakin zona terletak ke Barat maka sensasi termal yang dirasakan semakin tidak nyaman. Misalnya untuk zona Utara urutan zona yang paling nyaman adalah zone_17 (35,35\%), zone_14 (34,82\%) dan zone_11 $(34,08 \%)$. Anomali ditujukkan pada kelompok zona yang terletak di bagian Selatan yaitu antara zone_26 (34,11\%) dan zone_23 (34,25\%). Jika mengikuti tren zona Tengah dan Utara seharusnya zone_26 lebih nyaman dibandingkan dengan zone_23. Butuh penelitian lebih lanjut untuk dapat memastikan faktor yang menyebabkan anomali tersebut.

\section{KESIMPULAN}

Dari hasil simulasi yang didapatkan bahwa kurang dari $40 \%$ waktu sepanjang tahun dirasakan nyaman pada ruang GS-PAFT. Kondisi paling nyaman dirasakan pada zone_8 dengan persentase kenyamanan termal 39.23\%. Sementara kondisi paling tidak nyaman dirasakan pada zone_20 dengan 33.53\% waktu nyaman sepanjang tahun. Zone_8 yang merupakan zona paling nyaman terletak pada bagian tengah yang berbatasan dengan zona lainnya. Sementara zone_20 terletak di bagian Barat Daya dan zona ini memiliki dua bidang dinding yang ter-ekspos langsung dengan radiasi matahari.

Persepsi ketidaknyaman termal yang dirasakan pada semester genap 2016/2017, Februari sampai Juli, sejalan dengan hasil simulasi yang dilakukan pada studi ini. Pada semester tersebut mengalami kondisi paling tidak nyaman sepanjang tahun yaitu pada bulan Mei sampai Juli. Dengan studi ini dapat diketahui bahwa kondisi tidak nyaman karena sensasi panas berlangsung sepanjang tahun terutama pada siang sampai sore hari. Untuk itu perlu usaha perbaikan kondisi termal GSPAFT dengan tetap mempertimbangkan efisiensi pemakaian energi pada bangunan. Perbaikan dapat dilakukan dengan menggunakan data-data yang disajikan pada studi ini kemudian melakukan simulasi untuk kondisi perbaikan dengan metode seperti pada penelitian ini. Sehingga dapat menjamin ketepatan solusi untuk perbaikan kondisi termal. 


\section{ADAPTIVE COMFORT PADA GRAND STUDIO PROGRAM STUDI ARSITEKTUR FAKULTAS TEKNIK UNIVERSITAS MALIKUSSALEH

\section{DAFTAR REFERENSI}

ASHRAE Standard 55. 2010. Thermal Environmental Conditions for Human Occupancy. Atlanta: American Society of Heating, Refrigerating and Air-Conditioning Engineers, Inc.

Alozie, G, O.C Ifebi, and M.U Eze. 2015a. "An Assessment of Thermal Comfort in Naturally Ventilated Architectural Studio in Abia State University, Uturu." International Journal of Advance Studies in Engineering and Scientific Inventions 104-108.

Alozie, G, O.C Ifebi, and M.U Eze. 2015. "Thermal Comfort Evaluation of Two Naturally Ventilated Architectural Studios in Akanu Ibiam Federal Polytechnic Unwana Ebonyi State-Hot-Humid Environment." International Journal of Strategic Research in Education, Technology and Humanities 205-212.

Baruah, Plabita, Manoj Kumar Singh, and Sadhan Mahapatra. 2014. "Thermal Comfort in Naturally Ventilated Classrooms." 30th International Plea Conference. Ahmedabad. 1-8.

de Dear, Richard J, and Gail S Brager. 2002. "Thermal Comfort in Naturally Ventilated Buildings: Revisions to ASHRAE Standard 55." Energy and Buildings 549-561.

Groat, Linda, and David Wang. 2013. Architectural Research Methods: Second Edition. Hoboken: John Wiley \& Sons.

Kamaruzzaman, Khadijah, and A.S.B Tanzilan. 2012. "Thermal Comfort Assessment of a Classroom in Tropical Climate Conditions." Recent Advances in Energy, Environment and Development 87-91. 